\title{
Guest editorial New challenges for business actors and positive heuristics
}

\author{
Simone Guercini \\ University of Florence, Florence, Italy, and \\ Christian Lechner \\ Luiss Business School, Rome, Italy
}

\begin{abstract}
Purpose-The purpose of this guest editorial is to present an overview of the contributions in this special issue and proposes a positive approach to heuristics deriving from the growing interest in the decision-making topic with respect to the new challenges emerging in uncertain environments in management and marketing research.

Design/methodology/approach - The authors explore the reasons for a positive view of business actors' judgments and choices based on heuristics, not only in terms of effectiveness in practice, but their fit with human cognition and behavior, and the potential distinctiveness in contexts where technological devices and algorithms are more widespread, but not necessarily more appropriate.

Findings - The authors present and discuss the emergence and evolution of heuristics as a topic in the management literature, and the themes and insights proposed in the papers published in this special issue contributing to research aimed at systemizing a managerial perspective of the concepts and tools that may be useful for practitioners and researchers in this field.

Originality/value - The paper discusses the positive role that heuristics can play, offering some propositions for future research by framing heuristics as a set of tools (toolbox) for business actors in uncertain contexts, without constituting a cognitive limitation for effective solutions.
\end{abstract}

Keywords Positive heuristics, Uncertainty, Decision making, Adaptation, Business actors

Paper type Guest editorial

\section{Introduction}

The topic of heuristics has received increasing attention in management studies (Artinger et al., 2015; Bettis, 2017; Guercini and Milanesi, 2020) as a result of developments in other disciplines (psychology, cognitive sciences) and the evolution of the context in which business actors form their judgments and choices (Look and Hinnen, 2015). The business actors' environment is increasingly characterized by change and uncertainty, despite the availability of larger amounts of data and more powerful computing tools. New technologies impact decision-making, and the complex digital devices and artificial intelligence systems are capable of replacing business actors in their data search, selection, processing and choice tasks (Duan et al., 2019).

The cultural and social changes ensuing from technological advances or imposed by circumstances (such as the pandemic) have also digitalized socialization processes by way of new media, sustainability or social distancing requirements (Carroll and Buchholtz, 2014). Digitalization implies ever-increasing amounts of data and computable solutions to many problems through algorithms. While heuristics are often understood as rules of thumb (implying fuzziness), algorithms are a finite sequence of well-defined, computerimplementable instructions, typically used to solve a class of problems or perform computations (Hill, 2016). Heuristics played an essential role in the origin and development of artificial intelligence (Simon, 1995), as Gigerenzer and Todd (1999, p. 5) point out "heuristics can be seen as models of behavior of both living organisms and artificial systems."

The largest part of the debate on heuristics concerns, on the one hand, their ability to make accurate predictions, and on the other hand, the generation of biases (Kelman, 2011;

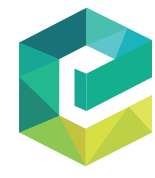

Management Decision Vol. 59 No. 7,2021 pp. $1585-1597$ 0025-1747 
$\mathrm{MD}$

59,7

1586

Gilovich et al., 2002; Gigerenzer et al., 1999; Guercini, 2012, 2019; Guercini et al., 2015). This special issue focuses on a positive perspective of heuristics. Why assume a positive view of heuristics in management studies? Despite the pressure toward data-driven precision, there appears to be validity in more fuzzy approaches (Martin, 2009). In Newell et al. (1962, p. 85), a positive view of heuristic problem-solving is defined as "any principle or device that contributes to the reduction in the average search to solution." Defining heuristics as a strategy that ignores available information, Todd and Gigerenzer (2012) use the term in relation to predictive accuracy in the fast and frugal approach (Gigerenzer and Todd, 1999; Gigerenzer and Brighton, 2009; Gigerenzer and Gaissmaier, 2011).

The positive view of heuristics has been the subject of debate in strategic management studies (Bingham and Eisenhardt, 2014; Vuori and Vuori, 2014), arguing that Gigerenzer's reasoning on the accuracy of predictions based on heuristics has less validity in the context of strategic decisions and that the greatest benefits might arise in the strategy implementation phase (Vuori and Vuori, 2014). This criticism starts from the assumption that cognition can be clearly separated from behavior, and hence strategy formulation from implementation, thus weakening claims for the effectiveness of heuristics only in implementation (Mintzberg, 1973).

While strategy formulation entails access to unlimited information, time and processing capabilities, strategy design requires skills beyond information processing, affected by behavior and heuristic mechanisms that can populate the creative processes, as well known in the use of analogy.

Interest in heuristics derives not only from their effectiveness (to solve problems) and accuracy as a prediction tool, as highlighted in the fast and frugal approach (Todd and Gigerenzer, 2012). Their diffusion and natural propensity for adoption by human decisionmakers is widely recognized even by those who deem heuristics a source of biased judgments (Tversky and Kahneman, 1974; Bettis, 2017). New technological tools and systems (Gigerenzer, 2011) constitute a factor of change and a source of challenges, in some respects unprecedented for individuals and organizations (Harari, 2018). Faced with these challenges, in this special issue, attention to positive heuristics is motivated by their particular fit or resonance with human cognition and behavior, the recognition of their diffusion in human activities, even by those considering heuristics as a source of biases (Kahneman, 2011). The study of the role of heuristics in management is attributable to the human component of business processes increasingly related to new digital technologies, whereby heuristics are potentially a source of advantages for actors in integrated business contexts (Guercini, 2020).

Moreover, the debate on heuristics vs algorithms might highly neglect a fundamental aspect: the implicit assumption is that algorithms are a substitute for heuristics and that algorithms will increasingly replace heuristics (Harari, 2018). However, heuristics and algorithms can also be complementary with the former acting as a form of pre-algorithm or fuzzy algorithm useful in some contexts, and the latter more useful in others (Martin, 2009). Gigerenzer's work builds a bridge to this view, demonstrating the effectiveness of certain heuristics when translating them into algorithms (e.g. see Gigerenzer and Todd, 1999).

With this reflection on the new challenges for business actors and heuristics in mind, this management decision special issue proposes a series of conceptual and empirical essays that explore the nature, evolution and application of heuristics by business actors, alongside the conditions and potential in the context in which these actors develop cognition and behavior. Indeed, the papers advance arguments proposing a positive view of heuristics as a resource for business actors.

\section{At the origin of research on heuristics and their role for business actors}

The interest in the topic of heuristics in management originated from Simon's (1957, 1967, 1990) contributions arguing that human beings rely on heuristics not only due to their 
cognitive limitations (Miller, 1956; Cowan, 2001) but also the task environment. Simon's interest in heuristics and problem-solving (Newell, 1981) was influenced by the mathematician Polya (1945) providing problem-solving methods and heuristic search as a problem-solving framework (Guercini, 2019) or "cognitive shortcuts that emerge when information, time, and processing capacity are limited" (Newell and Simon, 1972).

The subsequent literature streams have not generally denied the positive aspects of heuristics, even if overshadowed by negative aspects attributable to the heuristics and biases approach (Kahneman, 2003). The literature proposing dual process theories in the field of forming people's judgments and choices frequently highlights that intuitive processes are more natural or at least easier to activate in human decision-makers.

Market players, be they entrepreneurs, managers or consumers, are faced with the issue of uncertainty. How market players deal with uncertainty correlates with the widespread use and effectiveness of heuristics. Uncertainty includes limited predictability, the absence of pertinent data or ignorance about which data are relevant. While in such contexts the reliability of data-driven approaches is not questioned (they will consistently produce the same result), their validity in providing acceptable solutions has been challenged (Martin, 2009).

Indeed, the perception of increasing uncertainty has led heuristics back into the spotlight, which may seem paradoxical given the increase in available data and information. However, uncertainty cannot be solved with the collection of data, as by definition it is not measurable. In the sense of Knight's (1921, pp. 19-20) seminal work, "uncertainty must be taken in a sense radically distinct from the familiar notion of risk, from which it has never been properly separated ... risk means in some cases a quantity susceptible of measurement, while at other times it is something distinctly not of this character ... It will appear that a measurable uncertainty, or "risk" proper, as we shall use the term, is so far different from an unmeasurable one that it is not in effect an uncertainty at all. We shall accordingly restrict the term "uncertainty" to cases of the non-quantitative type. It is this "true" uncertainty, and not risk, as has been argued, which forms the basis of a valid theory of profit and accounts for the divergence between actual and theoretical competition."

Research on heuristics refers to cognitive limitations, or perhaps better, the characteristics of perception and the capacity for human categorization (Ehrig et al., 2021; Katsikopoulos et al., 2021). The literature on sensorial perceptions concludes that the variance of available information will increase the ignorance of relevant factors to be observed, while little variance in information will make observation less relevant (Miller, 1956). Increasing prediction accuracy is thus a function of making relative rather that absolute judgments, increasing the number of distinguishable modalities of an observed character or arranging the tasks sequentially (Miller, 1956).

Decision-making corresponds to different types of procedures and processes, including the forms of rule-based decision-making to which heuristics can be traced (March, 1994, p. 13, pp. 57 and ff.). March (2006) refers to three different notions of the origin of choices related to human behavior: a preexisting purpose for human behavior, the consistency of a procedure, and finally, the primacy of rationality that sees the effectiveness of behavior in relation to outcomes and objectives.

Evolutionary economics examines the concept of heuristics distinguished from routines, the latter garnering greater attention. According to Nelson and Winter (1982), heuristics can play an important role in strategy design, representing the non-routine part in highly complex contexts. While routines lead to low-variance replication and outcomes, heuristics act as decision-making signposts.

Tversky and Kahneman (1974) brought heuristics to the forefront, associating it with bias. First described as a means to make computers smarter, heuristics began to be used as a way to explain the reason why people are "not smart.” Gigerenzer's studies (e.g. Gigerenzer et al., 1999) 
led to a different perspective of heuristic processes as a means of "fast and frugal" decisionmaking. Complex problems, such as making future forecasts or defining a course of action under rigid time constraints, are formulated in real settings where the information, time and memory of decision-makers are limited. In such circumstances, the mind can resort to (1) logic rules, (2) statistics rules or (3) heuristic rules. Rules from logic and statistics have been linked to rational reasoning, while heuristic rules have instead been associated with intuitions viewed as mechanisms subject to errors and even irrationality. The translation of heuristics into formal models that can be tested reflect in some aspects of Gigerenzer and Todd's (1999) main scientific contribution to the evolution of heuristics research. Heuristics are broken down into three building blocks: (1) search rules-the way individuals look for information in the form of cues; (2) stopping rules-when any given search is to be interrupted; (3) decision rules-how the final decision can be made based on the information gathered (Gigerenzer and Brighton, 2009).

The translation of heuristics into formal models that can be tested is in some respects Gigerenzer's main contribution to the evolution of heuristics research. The effectiveness of heuristics depend on analyzing the past (hindsight) and scrutinizing the future (foresight); information for forecasting: underfitting versus overfitting; the relationship between the form of heuristics and the context (task environment); the relationship between heuristics and the community.

The role of heuristics as a development tool for business actors breaks with the assumption that complex problems require complex solutions and that in uncertain and complex contexts, simple solutions can be effective (Gigerenzer, 2007).

A prediction model that takes into account a great deal of information referable to a "training set" may be less accurate because it considers a lot of noise as well as structural elements. In this case, the model manifests an "overfitting" problem, mirroring that of "underfitting" that characterizes models that are too poor in parameters and consider too little information (Green and Armstrong, 2015). Eisenhardt and her colleagues (e.g. Sull and Eisenhardt, 2015) are aligned with the idea that simple and evolving rules cope better with complexity than complicated solutions. In their view, simple rules are characterized by a limited number of relevant rules, specific to a particular and well-defined task or situation, guiding behavior through setting constraints to potential action (Sull and Eisenhardt, 2015).

In the processes of evaluating foreign markets with greater potential, imitating competitors or previous experiences have proven effective techniques and are widely adopted. These are $d e$ facto rules of conduct applied and examined in the literature on analyzing external markets as criteria for selecting those with the greatest potential (Guercini and Milanesi, 2020).

Attention to heuristics in the activities of business actors is not associated with a standard perception. Indeed, "there is an important difference between the two typical applications of a strategy, fitting (fit a strategy to a given set of data) and generalization (use a strategy to predict new data). In fitting, it is usually true that the more parameters a model has, and the more information (cues) it uses, the better it will fit given data. In generalization, in contrast, more is not necessarily better. A computationally simple strategy that uses only some of the available information can be more robust, making more accurate prediction for new data, than a computationally complex, information-guzzling strategy that overfits ..." (Gigerenzer et al., 1999, p. 20). For this reason, simple models are parsimonious in the exclusion of data but also the exclusion of noise, therefore reducing the probability of overfitting. However, simple models bear the risk of being too ignorant, namely excluding relevant data and thus underfitting (Gigerenzer et al., 1999).

\section{Recent development in the interest in heuristics in the management literature} Heuristics are garnering increasing attention in the management literature, with often polarized and divergent points of view and positions. The relative polarization of this 
debate is a consequence of the different views of heuristics in the business and management literature, where contributions marry a vision close to that of the heuristics and biases research program (Manimala, 1992; Busenitz and Barney, 1997) compared with the fast and frugal heuristics research program (Mousavi and Gigerenzer, 2014; Luan et al., 2019) and simple rules research program (Bingham and Eisenhardt, 2011; Sull and Eisenhardt, 2015). Part of the reason for this polarization also corresponds to the strong heterogeneity in the definition of the concept. If there is convergence in identifying heuristics as a simplified resolution method compared to alternative analytical methods, there is not always clarity about the extent of this simplification. In psychology, exponents of the major schools of thought on the subject tend to identify and define different types of heuristics that are somehow specific to the school's research approach. Thus, availability or representation recalls the approach of Tversky and Kahneman (1974), while recognition or "take the best bets" evokes the approach of Gigerenzer and colleagues (Brighton and Gigerenzer, 2015).

Although studied for their effectiveness or the biases they generate, observation in the context of businesses and organizations in the field, they emerge and stand out above all for their identity that is difficult to establish. Heuristics can thus be innate but can also be learned. Experts, but even non-experts, make extensive use of them. They are characterized as ways of solving problems based on simple rules that make little use of information, without necessarily having a predefined threshold, so their simplicity ultimately appears to be a relative datum that depends on the more complex term with which to compare them. In mathematics, many problem-solving methods look for solutions based on simpler processes. For example, the so-called Monte Carlo method defines a class of approaches extensively used for a wide range of problems following a pattern of this type: (1) define a domain of possible input data; (2) generate random inputs from the domain with some given probability distribution; (3) perform a deterministic calculation using the input data; (4) aggregate the results of the individual calculations into the final result.

Heuristics are positioned on different levels, so meta heuristics can be identified in a context, but also heuristics detailing the execution, thus comparing heuristics with simple rules according to Eisenhardt and colleagues. Each heuristics research program proposes specific forms and classifications, hence lack of agreement starts from the definition in many respects, even if acknowledging the rules according to Simon.

Heuristics have been addressed in strategic management (Bingham and Eisenhardt, 2011; Bettis, 2017) and other fields, including marketing (Guercini et al., 2015), distribution, pricing and communication (Artinger et al., 2015).

Decision-making is a relevant topic in the management and entrepreneurship field. Managerial decision-making in the strategic (and especially entrepreneurial) context is characterized by a high degree of uncertainty regarding the future development of predominantly complex systems. Understanding how individuals make decisions under uncertainty is thus pivotal (Hammond, 1996).

Different research approaches attempt to understand decision-making under uncertainty and develop models that better explain real-world decision-making processes, resulting in improved theories and recommendations. For instance, intuition, sometimes defined as "choices made without obvious formal analysis" (Behling and Eckel, 1991, p. 47) is no longer deemed as always inferior. Yet, there is neither a clear definition of intuition, especially a delineation between gut feeling (without experience) and expert intuition (based on past experiences), nor a systematization of the related concepts and terminologies, such as positive rational heuristics (Bingham and Eisenhardt, 2011), negative heuristics or decision-making biases (e.g. Kahneman, 2011; Tversky and Kahneman, 1974; Thaler, 1994), affective rationality and affective heuristics. In addition, the differentiation between experiential and analytical systems as two generic human perception, judgment and decision-making means 
(Slovic et al., 2004), or the different forms and views of rationality that include fast and frugal heuristics as a sub-category of bounded rationality (Gigerenzer and Todd, 1999), have also been neglected.

While cognitive biases point toward the negative side of non-analytical decision-making, positive heuristics express the view that simply rules can be more effective or the only feasible option in given situations for making appropriate decisions, considering their effectiveness beyond ideological prejudices (Gigerenzer and Marewski, 2015).

As a result of the task environment, methods that are effective for analyzing data insights are not the same as for analyzing data foresight. Research has to consider the conditions under which entrepreneurs and managers are more effective when relying on intuition (see Bird, 1988, and earlier Gragg, 1940), and the conditions under which they are more effective when relying on analysis (see Segars and Grover, 1998; on other factors, such as experience related to intuitive decision-making, see Dane, 2010). Research examining the decision-making processes adopted by managerial experts confirms the diffusion and perception of the effectiveness of decision-making methods based on heuristic rules (Maidique, 2011; Guercini et al., 2015).

One could argue that technology increasingly makes a great deal of information available to economic actors, as well as the great ability to compute and synthesize data in analytics (big data management). While this enables tackling many problems, it also requires adapting the availability of big data to individuals' capabilities in view of their cognitive limitations. Given increasing data availability, the question arises as to what role heuristics might still play in managerial decision-making (Artinger et al., 2015).

This special issue brings together experts in theories of individual judgment with experience and interest in entrepreneurship and management, and experts on entrepreneurship and management with experience and interest in individual judgment. The contributions in this special issue include examples of heuristics, simple rules and adaptive toolboxes used in specific business cases and contexts (industries, local systems etc.), simple rules used in specific decision-making processes (entry in international markets, innovation processes etc.), rule-based decision-making theory in relation to management wisdom, cognitive dimensions of framing, individual and collective cognition, the scope and effectiveness of heuristics that business actors adopt in relation to context variables and actions, delineating heuristics from other forms of bounded rational decision-making and the impact on organizations.

This special issue therefore focuses on heuristics and forms of judgment based on heuristics as simple rules that business actors use in contexts characterized by the increasing availability of information technologies (big data, artificial intelligence, marketing automation tools, etc.), and at the same time, growing uncertainty. Business actors include entrepreneurs, managers and entire organizations. Entrepreneurship and management theories focus on either the capabilities of individuals or the resources of organizations, thus incomplete to the extent that, as Herbert Simon and James March argued, success comes from the match between the individual and the organization.

In these papers, heuristics are not abstract categories to be compared with other decisionmaking methods but are first of all a current reality confronted with practice and experience. Heuristics are therefore above all learned, and the mechanisms of learning and stratification/ articulation of the heuristic rules are an important component of the experience of organizational actors.

\section{Contributions in this special issue}

We next summarize the contributions of the seven papers in this special issue.

Taking a general perspective, Cavaretta (2021) and Atanasiu (2021) examine the biological and social origins of heuristics and subsequent evolution both as single rules and as a combination of adopted rules. 
Cavaretta focuses on a theme insufficiently developed in the literature, namely individual rules and their effectiveness, and the emergence of small bundles of rules that drive behavior. In particular, this strictly conceptual article elaborates on the way such bundling is realized, intertwined with the different ways through which heuristics emerge, including a dimension learned in a social context or innate on a biological basis. While combining heuristics in small bundles is potentially a complex process, the author highlights that research has shown that the process is evolutionary, characterizing the biological and social dimensions in different but similar terms. The paper therefore recognizes the micro dimensions (e.g. managerial beliefs) of individual heuristics, and the macro dimensions (for example, social movements) in the formation of bundles of heuristics that might characterize the managerial context. Discussing the size of the bundles of heuristics, how they form and evolve, the author concludes that "the social calculations of small heuristics bundles may constitute a crucial mechanism for the elaboration of pragmatic theories of action."

The article by Atanasiu (2021) tackles a similar issue but adopts a different perspective and approach. In particular, the author presents a review of the literature to address the issue of the origin and lifecycle of heuristic rules.

As such, while Cavaretta's study addresses the issue of the origins of heuristics at the micro and macro level, Atanasiu takes a longitudinal view of the way in which heuristics emerge, affirm and mature. This dynamic perspective starts from the often static elements offered by existing studies, linking the theme to proverbs, their affirmation and diffusion. Using research results from other disciplinary fields, the author examines the proverbialization process in the field of paremiology, suggesting links with ethnographic methodologies for the empirical development of research on the topic. The paper therefore offers "insights on how heuristics originate from experienced managers" and the process of "proverbialization, refining, adapting," with sharing "either in an informal way, through socialization, or in formal way, through regular meetings."

The other articles in this special issue examine more specific issues through empirical research focusing on single typologies of heuristics. In particular, the article by Ranganathan (2021) examines the role of personal value systems as a relevant antecedent for decisions and the relationship with risk taking. The study includes a discussion of the literature and an empirical part exploring the theme of satisficing seen as positive heuristics that assume importance for individuals in defining risk, examining the risk elicitation techniques that Berg developed. The paper adopts the Short Schwartz Value Survey (SSVS) as a reference value scale, while the empirical part refers to the relationship between personal value systems and risk in the field of decisions in the financial sector. The contributions of the article are twofold. On the one hand, "it extends the positive view of heuristics, especially in the domain of risk elicitation, where the expected utility approach is the reigning basis for modeling decisions under risk", and on the other hand, "our findings establish structural links between the risk elicitation method based on Simon's concept of satisficing and inherent elements such as personal value systems."

The article by Galavotti et al. (2021) focuses on a specific heuristic rule, namely heuristic representativeness in decision processes. The paper is conceptual and integrates conflicting theories or dual process theories using the adaptive toolbox approach to provide the building blocks of representativeness heuristics. The authors face the interesting challenge of incorporating different approaches in the literature, as their analysis "is conducted by integrating elements of contrasting theoretical perspectives". In particular, their framework adopts "a modeling approach based on building blocks, as developed by the fast and frugal perspective, to structure a heuristic rule that was introduced by the heuristics and biases approach." Finally, in their discussion, the authors examine the role of experience, intuition and overconfidence with respect to representativeness in decision-making.

Greco et al. (2021) examine the relationship between organizational identity and individual heuristics. In the words of the authors, this article proposes "a theory on identity reflexivity as 
a cognitive mechanism of strategy change." The study is based on findings that make use of qualitative methodologies, and more precisely, a two-year ethnographic study of a Dutch social housing association. This organization has both a social and an economic goal, generating a dual identity, as "identities specify the practices through which values are pursued". The theme of identity (whether individual or organizational) is closely linked to rule-based decision-making (and thus heuristics). Therefore, the study offers a perspective on the relationship between organizational and individual heuristics, with particular reference to the relationship between organizational identity and individual heuristics. The authors then examine the issue of conflicting identities in a dual-identity organization, and the role that the relationship between individual and organizational heuristics plays in a context of strategic change. As a main result, it emerges that "despite conflicting interpretations and visions between two predominant identities, paths of cognitive shortcuts - here conceptualized as internal and external identity reflexivity - are shared by the conflicting identities."

The article by Gilbert-Saad et al. (2021) examines the use of heuristics under uncertainty by experienced or inexperienced decision-makers. The authors recall that research has predominately focused on the adoption of heuristics by expert decision-makers, and the adoption by less experienced decision-makers is relatively less studied. The paper addresses this gap in the literature and presents an empirical study conducted on a sample of inexperienced entrepreneurs in a marketing context where they have to set prices and select a distribution channel in a hypothetical company. The authors then examine different levels of heuristics, arguing that "there are three types of heuristics (metacognitive, representing criteria, and detailing the execution) serving different functions in the decision-making process. The participants in our study moved from broad to more specific heuristics as they approached a solution." Furthermore, "the use of heuristics may be self-regulated. Our findings suggest that non-expert decision-makers can use adaptive toolboxes of heuristics in unfamiliar domains and provide the first list and categorization of the heuristics that entrepreneurs use to choose marketing channels and set prices." The authors then discuss a particular business area-marketing-in which the use of heuristic rules by entrepreneurial decision-makers are identified as metacognitive heuristics, criteria heuristics and implementation heuristics.

In their article, Rauwerda and De Graaf (2021) examine how heuristics are used in practice in a particular field, namely by managers in organizations that deliver financial advisory services to SMEs. The research is based on a qualitative study conducted through group interviews and discussions using a semi-structured questionnaire. The article highlights the importance of the use of heuristics for this particular category of decision-makers in the financial consulting business, the adoption of a less-is-more approach, and the use of simple rules to decide the approach to follow. The authors also highlight the complexity and difficulties in understanding the ecological rationality behind the use of these simplified decision-making principles and rules by a group of actors attributable to a particular category in a specific context. In particular, "Financial advisers to SMEs use cognitive shortcuts and simple rules to advise SME-owners, based on previous experiences, but it is difficult to determine whether that leads to the same or even better solutions for them and their clients than using probability theory and financial optimization models." The authors highlight the role of interaction with clients (in this case, SME owners) and evaluating the advisers' day-to-day decisions in a process where satisficing and interactions (with clients and their own organization) are key to modeling the simple rules adopted by advisers.

Finally, in their article closing this special issue, Ehrig et al., 2021 and Katsikopoulos et al., 2021 present the results of an exploratory empirical study on price anticipation in central and investment banks. Conducting qualitative interviews with managers who are part of teams tasked with anticipating prices, the authors highlight the conditions of strategic uncertainty in which managers operate, uncertainty relating to other market participants, their decisions 
and the related consequences. The conditions in which agents conduct price anticipation can therefore be traced back to non-calculable risk, as strategic uncertainty can lead to intractable calculations, and the probabilities of the results are unknown and unknowable. The authors therefore postulate the use of simple rules or heuristics, and through the interviews identify and describe the characteristics of the heuristics bankers of central and investment banks use in the anticipation of prices. In the context of the Gerd Gigerenzer's fast and frugal research program, this study offers an original contribution on the heuristics used in the price anticipation process of leading financial players.

\section{Conclusions: positive heuristics and business actors' adaptive toolbox}

Positive heuristics allow making accurate predictions under certain circumstances. Nevertheless, business actors face the emergence of new tools developed through artificial intelligence, in other words, the algorithmic threat. However, a positive view of heuristics encompasses three factors. First, aesthetics, when heuristics are substitutes for complex solutions. This is the case when heuristics are the parsimonious solution, or once translated, the simplest algorithm (Gigerenzer and Todd, 1999). Second, uncertainty. Heuristics act as complements, the pre-algorithmic solution that reduces the field of valid solutions under uncertainty. They are the necessary intermediate step before an algorithm can be developed. Third, human behavior. When the task-specific solution requires human interaction, it might remain the most effective solution, since it resonates with behavior and limited cognition.

While heuristics can be adopted and associated with accurate or in any case effective predictions, the change in context can push (human) business actors to increasingly externalize decision-making tasks, specializing in tasks in which they excel and to which they are most suited. In this way, heuristics can contribute positively as a complement to new tools and systems based on artificial intelligence (Ehrig et al., 2021; Katsikopoulos et al., 2021). If considering solutions to problems in a process perspective, then heuristics relate to the exploration of solutions and the reduction of the possible solution space, and algorithms to exploitation.

The articles in this special issue offer insights on the topic of heuristics, comparing the effectiveness of individual rules to highlight some relevant taxonomies in the management perspective. In particular, bundle of heuristics vs single heuristics, innate heuristics vs learned heuristics (Cavaretta, 2021), lifecycle of heuristics (Atanasiu, 2021), organizational heuristics vs individual heuristics (Greco et al., 2021). These are useful distinctions and in some respects already touched upon in the literature when distinguishing heuristics from experience vs heuristics designed by managers and consultants (Bettis, 2017; Casson, 2016).

The thesis supported is that heuristics are positive in that they enhance specific characteristics of the human decision-maker in a context where the boundaries of the tasks to be undertaken in the business context are uncertain, while others may progressively move toward more advanced forms of artificial intelligence. As Simon (1995, p. 97) pointed out, the way in which humans achieve intelligence differs from the way in which computers perform computations, and as such, the difference lies in the characteristics of heuristic processes. The study of heuristics has been key to creating artificial intelligence algorithms and make computers smart, offering a creative, imperfect and therefore adaptive side, together with modeling a limited number of parameters, and as such, easily manageable by the human actor. Therefore, heuristics are positive with respect to the role of the human actor in the future business environment. The positive role of heuristics for business actors is determined not only by the characteristics of individual heuristics, but by the adaptive toolbox as a whole.

In conclusion, we examine four propositions concerning this adaptive toolbox, already partly considered for the simple rules described by Eisenhardt and colleagues (e.g. Sull and Eisenhardt, 2015). 
$\mathrm{MD}$

59,7

1594

The first proposition concerns the characteristics of the bundle of heuristics available to the single actor, given limited cognition. While experience might strengthen the capacity to use heuristics more effectively, this capacity will be limited. Therefore: (P1) The growth in experience of the single actor has to produce not only learning, but a "vigilant" attitude of the heuristic rules that are part of this portfolio, whose raison d'etre is only validity and effectiveness, thus leading to new heuristics and the elimination of "obsolete" heuristics. Due to a change in the context, or if no longer effective, they should be promptly eliminated from the portfolio.

The second proposition concerns the number of heuristics needed in the adaptive toolbox: (P2) There is a decreasing return in the addition of new heuristics. The number of heuristics decreases the efficiency as simply rules. The effectiveness of heuristics lies in their incompleteness allowing for flexibility and exploration of new heuristics. There is a "tradeoff" between the advantage given by the utility provided with the addition of a new heuristic rule and the loss of flexibility that could derive from a larger portfolio in real decision-making. While eliminating heuristics can lead to the underutilization of past experience and increase the possibility of repeating errors, an excessive number of heuristic rules can reduce the promptness of response in relation to the need to consult a wider repertoire when not contradictory (Switzer and Sniezek, 1991; Wilson and Schooler, 1991).

The third proposition again refers to the number of heuristics used by a single business actor: (P3) Companies can reduce the number of heuristics in their portfolio also to maintain what is defined as "neural plasticity", understood as the ability of the cognitive system to change and evolve. The concept of neural plasticity is well-established in the literature (Anderson, 2010). In this sense, a low number of heuristics can make it easier to add new heuristics when needed, while maintaining flexibility given the conditions of non-saturation of the storage capacity (Cowan, 2001).

This leads us to the fourth and final proposition on the complementarity between heuristics and algorithms: (P4) Companies can increase neural plasticity by establishing organized processes with the task of studying and translating established heuristics into algorithms. The reduction of heuristics would thus allow exploring new heuristics in contexts characterized by uncertainty.

In essence, while algorithmic solutions will increase the exploitation capacity of business actors, heuristics will sustain the exploration capacity while dealing with complexity and uncertainty.

To conclude, this special issue is a first step in the positive and complementary view of heuristics, which we hope will lead to more integrative research on algorithms and heuristics.

\section{References}

Anderson, M. (2010), "Neural reuse: a fundamental organizational principle of the brain", Behavioral and Brain Sciences, Vol. 33 No. 4, pp. 245-266.

Artinger, F., Petersen, M., Gigerenzer, G. and Weibler, J. (2015), "Heuristics as adaptive decision strategies in management”, Journal of Organizational Behavior, Vol. 36 No. S1, pp. S33-S52.

Atanasiu, R. (2021), "The lifecycle of heuristics as managerial proverbs", Management Decision, Vol. 59 No. 7, pp. 1617-1641.

Behling, O. and Eckel, N.L. (1991), "Making sense out of intuition", Academy of Management Executive, Vol. 51, pp. 46-54.

Bettis, R.A. (2017), "Organizationally intractable decision problems and the intellectual virtues of heuristics", Journal of Management, Vol. 43 No. 8, pp. 2620-2637.

Bingham, C.B. and Eisenhardt, K.M. (2011), "Rational heuristics. The 'simple rules' that strategists learn from process experience”, Strategic Management Journal, Vol. 32, pp. 1437-1464. 
Bingham, C.B. and Eisenhardt, K.M. (2014), "Response to Vuori and Vuori's commentary on "Heuristics in the strategy context", Strategic Management Journal, Vol. 35 No. 11, pp. 1698-1702.

Bird, B. (1988), "Implementing entrepreneurial ideas: the case of intention", Academy of Management Review, Vol. 13 No. 3, pp. 442-453.

Brighton, H. and Gigerenzer, G. (2015), "The bias bias”, Journal of Business Research, Vol. 68 No. 8, pp. 1772-1784.

Busenitz, L.W. and Barney, J.B. (1997), "Differences between entrepreneurs and managers in large organizations: biases and heuristics in strategic decision-making”, Journal of Business Venturing, Vol. 12 No. 1, pp. 9-30.

Carroll, A.B. and Buchholtz, A.K. (2014), Business and Society: Ethics, Sustainability, and Stakeholder Management, Cengage Learning.

Casson, M. (2016), “Alan Rugman's methodology”, International Business Review, Vol. 25, pp. 758-766.

Cavaretta, F.L. (2021), "On the hard problem of selecting bundles of rules: a conceptual exploration of heuristics emergence processes”, Management Decision, Vol. 59 No. 7, pp. 1598-1616.

Cowan, N. (2001), "The magical number 4 in short-term memory: a reconsideration of mental storage capacity", Behavioral and Brain Sciences, Vol. 241, pp. 87-114.

Dane, E. (2010), "Reconsidering the trade-off between expertise and flexibility: a cognitive entrenchment perspective", Academy of Management Review, Vol. 35, pp. 579-603.

Duan, Y., Edwards, J.S. and Dwivedi, Y.K. (2019), "Artificial intelligence for decision making in the era of big data: evolution, challenges and research agenda", International Journal of Information Management, Vol. 48, pp. 63-71.

Ehrig, T., Katsikopoulos, K., Jost, J. and Gigerenzer, G. (2021), "An exploratory study of heuristics for anticipating prices”, Management Decision, Vol. 59 No. 7, pp. 1750-1761.

Galavotti, I., Lippi, A. and Cerrato, D. (2021), "The representativeness heuristic at work in decisionmaking: building blocks and individual-level cognitive and behavioral factors", Management Decision, Vol. 59 No. 7, pp. 1664-1683.

Gigerenzer, G. (2007), Gut Feelings: The Intelligence of the Unconscious, Penguin.

Gigerenzer, G. (2011), "Outsourcing the mind", in Brockman, J. (Ed.), Is the Internet Changing the Way You Think? The Net's Impact on Our Minds, and Future, Harper, New York, NY, pp. 147-149.

Gigerenzer, G. and Todd, P.M. (1999), "Fast and frugal heuristics: the adaptive toolbox", in Gigerenzer, G., Todd, P.M. and The ABC Research Group (Eds), Simple Heuristics that Make Us Smart, Oxford University Press, pp. 3-34.

Gigerenzer, G. and Brighton, H. (2009), "Homo heuristicus: why biased minds make better inferences", Topics in Cognitive Science, Vol. 11, pp. 107-143.

Gigerenzer, G. and Gaissmaier, W. (2011), "Heuristic decision making”, Annual Review of Psychology, Vol. 26, pp. 451-482.

Gigerenzer, G. and Marewski, J.N. (2015), "Surrogate science: the idol of a universal method for scientific inference", Journal of Management, Vol. 412, pp. 421-440.

Gigerenzer, G., Todd, P.M. and The ABC Research Group (1999), Simple Heuristics that Make Us Smart, Oxford University Press.

Gilbert-Saad, A., NcNaugton, R.B. and Siedlok, F. (2021), "Inexperienced decision-makers' use of positive heuristics for marketing decisions", Management Decision, Vol. 59 No. 7, pp. 1706-1727.

Gilovich, T., Griffin, D. and Kahneman, D. (2002), Heuristics and Biases: The Psychology of Intuitive Judgment, Cambridge University Press.

Gragg, C.I. (1940), Because Wisdom Can't Be Told., Harvard University Press.

Greco, A., Long, T. and de Jong, G. (2021), "Identity reflexivity: a framework of heuristics for strategy change in hybrid organizations", Management Decision, Vol. 59 No. 7, pp. 1684-1705. 
Green, K.C. and Armstrong, J.S. (2015), "Simple versus complex forecasting: the evidence", Journal of Business Research, Vol. 68 No. 8, pp. 1678-1685.

Guercini, S. (2012), "New approaches to heuristic processes and entrepreneurial cognition of the market", Journal of Research in Marketing and Entrepreneurship, Vol. 14 No. 2, pp. 199-213.

Guercini, S. (2019), "Heuristics as tales from the field: the problem of scope", Mind and Society, Vol. 18 No. 2, pp. 191-205.

Guercini, S. (2020), "The Actor or the machine? The strategic marketing decision-maker facing digitalization", Micro and Macro Marketing, Vol. 291, pp. 3-7.

Guercini, S. and Milanesi, M. (2020), "Heuristics in international business: a systematic literature review and directions for future research", Journal of International Management, Vol. 26 No. 4, p. 100782.

Guercini, S., La Rocca, A., Runfola, A. and Snehota, I. (2015), "Heuristics in customer-supplier interaction”, Industrial Marketing Management, Vol. 48, pp. 26-37.

Hammond, K.R. (1996), Human Judgment and Social Policy: Irreducible Uncertainty, Inevitable Error, Unavoidable Injustice, Oxford University Press on Demand.

Harari, Y.N. (2018), 21 Lessons for the 21st Century, Jonathan Cape, London.

Hill, R.K. (2016), "What an algorithm is", Philosophy and Technology, Vol. 29 No. 1, pp. 35-59.

Kahneman, D. (2003), "Maps of bounded rationality: psychology for behavioral economics", American Economic Review, Vol. 93 No. 5, pp. 1449-1475.

Kahneman, D. (2011), Thinking, Fast and Slow, Macmillan.

Katsikopoulos, K., Simsek, O., Buckmann, M. and Gigerenzer, G. (2021), Classification in the Wild: The Science and Art of Transparent Decision Making, MIT Press.

Kelman, M. (2011), The Heuristics Debate, Oxford University Press.

Knight, F. (1921), Risk, Uncertainty and Profit, Houghton Mifflin.

Loock, M. and Hinnen, G. (2015), "Heuristics in organizations: a review and a research agenda", Journal of Business Research, Vol. 68 No. 9, pp. 2027-2036.

Luan, S., Reb, J. and Gigerenzer, G. (2019), "Ecological rationality: fast-and-frugal heuristics for managerial decision making under uncertainty", Academy of Management Journal, Vol. 62 No. 6, pp. 1735-1759.

Maidique, M.A. (2011), “The leader's toolbox”, Working Paper, Florida International University.

Manimala, M.J. (1992), "Entrepreneurial heuristics: a comparison between high PL (pioneeringinnovative) and low PI ventures", Journal of Business Venturing, Vol. 7 No. 6, pp. 477-504.

March, J.G. (1994), Primer on Decision Making: How Decisions Happen, Simon and Schuster.

March, J.G. (2006), "Rationality, foolishness, and adaptive intelligence", Strategic Management Journal, Vol. 27 No. 3, pp. 201-214.

Martin, R. (2009), The Design of Business: Why Design Thinking Is the Next Competitive Advantage, Harvard Business Press.

Miller, G.A. (1956), "The magical number seven plus or minus two: some limits on our capacity for processing information", Psychological Review, Vol. 63, pp. 91-97.

Mintzberg, H. (1973), "Strategy-making in three mode", California Management Review, Vol. 16 No. 2, pp. $44-53$.

Mousavi, S. and Gigerenzer, G. (2014), "Risk, uncertainty, and heuristics", Journal of Business Research, Vol. 67 No. 8, pp. 1671-1678.

Nelson, R.R. and Winter, S. (1982), An Evolutionary Theory of Economic Change, The Belknap Press, Cambridge MA.

Newell, A. (1981), The Heuristic of George Polya and its Relations to Artificial Intelligence, CarnegieMellon University. 
Newell, A. and Simon, H.A. (1972), Human Problem Solving, Prentice-hall, Englewood Cliffs, New Jersey, NJ.

Newell, A., Shaw, J.C. and Simon, H.A. (1962), "The processes of creative thinking”, in Gruber, H.E., Terrell, G. and Wertheimer, M. (Eds), Contemporary Approaches to Creative Thinking: A Symposium Held at the University of Colorado, Atherton Press.

Polya, G. (1945), How to Solve it: A New Aspect of Mathematical Method, Princeton University Press.

Ranganathan, K. (2021), "Do personal values explain variation in satisficing measures of risk?", Management Decision, Vol. 59 No. 7, pp. 1642-1663.

Rauwerda, K. and De Graaf, F.J. (2021), "Heuristics in financial decision making: the selection of SME financing by advisers in an increasingly diverse market", Management Decision, Vol. 59 No. 7 , pp. 1728-1749.

Segars, A.H. and Grover, V. (1998), "Strategic information systems planning success: an investigation of the construct and its measurement", MIS Quarterly, Vol. 22 No. 2, pp. 139-163.

Simon, H.A. (1957), Models of Man; Social and Rational, John Wiley and Sons.

Simon, H.A. (1967), "The logic of heuristic decision making”, in Rescher, N. (Ed.), The Logic of Decision and Action, The University of Pittsburg Press, pp. 1-20.

Simon, H.A. (1990), "Invariants of human behavior", Annual Review of Psychology, Vol. 41 No. 1, pp. 1-20.

Simon, H.A. (1995), “Artificial intelligence: an empirical science”, Artificial Intelligence, Vol. 77 No. 1, pp. 95-127.

Slovic, P., Finucane, M., Peters, E. and MacGregor, D. (2004), "Risk as analysis and risk as feelings: some thoughts about affect, reason, risk, and rationality", Risk Analysis, Vol. 24 No. 2, pp. 311-322.

Sull, D.N. and Eisenhardt, K.M. (2015), Simple Rules: How to Thrive in a Complex World, Houghton Mifflin Harcourt.

Switzer, F.S. III and Sniezek, J.A. (1991), "Judgment processes in motivation: anchoring and adjustment effects on judgment and behavior", Organizational Behavior and Human Decision Processes, Vol. 49 No. 2, pp. 208-229.

Thaler, R.H. (1994), Quasi Rational Economics, Russell Sage Foundation.

Todd, P.M. and Gigerenzer, G.E. (2012), "What is ecological rationality", in Todd, P.M., Gigerenzer, G.E. and The ABC Research Group (Eds), Ecological Rationality: Intelligence in the World, Oxford University Press.

Tversky, A. and Kahneman, D. (1974), "Judgment under uncertainty: heuristics and biases", Science, Vol. 185 No. 4157, pp. 1124-1131.

Vuori, N. and Vuori, T. (2014), "Comment on 'heuristics in the strategy context' by Bingham and Eisenhardt (2011)", Strategic Management Journal, Vol. 35 No. 11, pp. 1689-1697.

Wilson, T.D. and Schooler, J.W. (1991), "Thinking too much: introspection can reduce the quality of preferences and decisions", Journal of Personality and Social Psychology, Vol. 60 No. 2, pp. 181-192.

For instructions on how to order reprints of this article, please visit our website:

www.emeraldgrouppublishing.com/licensing/reprints.htm

Or contact us for further details: permissions@emeraldinsight.com 